\title{
Qualitative Analysis Of Styloid Process In OPGS of Patients who do not have Symptoms Of Eagle's Syndrome
}

Research Article

\author{
P. Deeksheetha ${ }^{1}$, Jayanth Kumar Vadivel ${ }^{2 *}$, Nashra Kareem ${ }^{3}$
}

${ }^{1}$ Saveetha Dental College and Hospitals, Saveetha Institute of Medical and Technical Sciences, Saveetha University, Chennai, India.

${ }^{2}$ Associate Professor, Department of Oral Medicine, Saveetha Dental College and Hospitals, Saveetha Institute of Medical and Technical Sciences, Saveetha University, Chennai, 600077, India.

${ }^{3}$ Senior Lecturer, Department of Periodontics, Saveetha Dental College and Hospitals, Saveetha Institute of Medical and Technical Sciences, Saveetha University, Chennai, 600077, India.

\section{Abstract}

\begin{abstract}
The aim of this study was to evaluate the styloid process and its anatomical variations on the orthopantomographs (OPG) of patients who do not have symptoms of Eagle's syndrome. The styloid process arises from the temporal bone. The normal length of the styloid ranges between 20 to $30 \mathrm{~mm}$. Any elongations beyond the normal range is considered as an elongated styloid process. Three muscles originate from the styloid process, the styloglossus, stylohyoid, and stylopharyngeus. This study was carried in a random sample of 100 patients (50 males and 50 females), who were divided into two age groups, 10-40 years of age and 41-70 years of age. The orthopantomographs used for the assessment of the styloid process was obtained by reviewing the case sheets of the patients visiting the hospital. The data was collected and tabulated in the excel sheets, and was transferred to the SPSS software for statistical analysis. From the present study, it was evident that the normal type of styloid process was observed on both sides.(right side- $40 \%$ and left side 38\%). The most common type of calcification of styloid processes found in the right and left sides were the partially calcified type. (Right- $48 \%$ and left- $57 \%$ ). Partially calcified type of styloid process was commonly observed in both age groups. (10-40 years :30\%, $41-70$ years: $18 \%$ on the right side and $10-40$ years: $32 \%, 41-70$ years: $25 \%$ ).
\end{abstract}

Keywords: Calsification; Eagle's Syndrome; Mineralization; Styloid Process.

\section{Introduction}

The styloid process is derived from the Reichert's cartilage of the second branchial arch. It is a cylindrical bony projection, The normal length of the styloid process ranges from 20 to $30 \mathrm{~mm}$. Any lengthening of the styloid process over $30 \mathrm{~mm}$ is considered as an elongated styloid process (ESP) [1]. The apex of the styloid process it's in close relation to the internal and External carotid arteries, the facial nerve runs anteriorly and medially to the styloid process [2]. Elongation and morphological changes of the styloid process is commonly an Anatomical alteration or a change developed with age. The word styloid is derived from the Greek word 'stylos', Meaning for a pillar. In about $4 \%$ of the population with elongated styloid process, there is a chance for the occurrence of eagle's syndrome [3]. Eagle's syndrome can be characterised by dull, aching pain localised in the throat, with or without a referred pain to the ear; and to the Mastoid region of the affected site. Dysphagia is uncommon yet one of the main symptoms in patients with Eagle's syndrome [4]. In normal circumstances the styloid process is generally composed of embryonic cartilage which can serve as a potential for its ossification [5].

Even though the elongation and mineralisation of the styloid process can be viewed and assessed on the OPGs, There are chances for distortions and inconsistencies as orthopantamographs are primarily obtained for the Visualisation of the teeth and the associated structures. The inconsistencies and distortions are mainly because the styloid process lies outside the focal trough of the OPGs [6]. Oftentimes radiographic features are never adequate for diagnosing a condition or a syndrome. The classification for the anatomical variations of the styloid process was proposed by Lang Lais et al, It can be broadly divided into two; which is, type

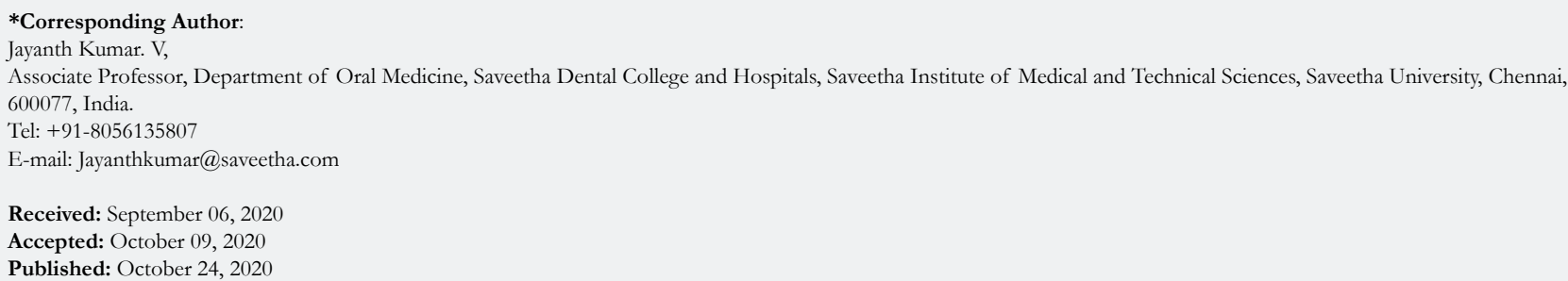

Citation: P. Deeksheetha, Jayanth Kumar Vadivel, Nashra Kareem. Qualitative Analysis Of Styloid Process In OPGS of Patients who do not have Symptoms Of Eagle's Syndrome. Int J Dentistry Oral Sci. 2020;7(10):892-897. doi: http://dx.doi.org/10.19070/2377-8075-20000177

Copyright: Jayanth Kumar. $\mathbf{V}^{\odot} 2020$. This is an open-access article distributed under the terms of the Creative Commons Attribution License, which permits unrestricted use, distribution and reproduction in any medium, provided the original author and source are credited. 
of elongation and pattern of mineralisation or calcification. The type of elongation can be further divided into normal type, elongated, pseudoelongated and segmented. The pattern of calcification Of the styloid process can be divided into partially calcified, nodular complex, calcified outline, completely calcified [7]. Assessment of parameters such as length of styloid process along with circumferences of ulnar notches, radial neck, radial tuberosity has been proved effective for orthopaedic surgeons for making prosthesis of the radial head and distal end of the radius in cases of trauma or in cases of tumour in those regions and also for the reconstruction of the bicipital tendon [8].

There have been reports to show that pain due to an elongated styloid process presenting in the nasopharyngeal carcinoma [911]. There have also been scenarios where the pain of an elongated styloid process was considered to be a pain due to burning mouth syndrome or neurologic problem, and prescription of needless drugs $[12,13]$.

The aim of the study is to perform qualitative analysis of the styloid process from the OPGs of patients who do not have symptoms of Eagle's syndrome in terms of type of elongation and calcification.

\section{Materials and Methods}

This was a university-based study. This was a unicentred retrospective study. The ethical board clearance was obtained from their institutional ethics committee (Ethical approval number: SDC/SIHEC/2020/DIASDATA/0619-0320). The data (OPGs) was obtained by reviewing 86,000 case sheets of patients reporting to Saveetha Dental College and hospitals from June 2019 to March 2020.

\section{Sampling}

In this study, a simple random sampling method was used. The study consisted of 100 patients, of which 50 were male patients and 50 female patients. They were categorised into two based on age, 10 to 40 years of age and 41 to 70 years. The external validity of the study was good as this was carried out in a clinical set up and the results obtained can be generalisable in a population belonging to the same ethnicity.

\section{Data collection}

The OPGs required were collected by reviewing the case sheets of the 100 patients. The length of the styloid process was assessed objectively, a styloid is considered elongated when the process extends beyond the ramus of the mandible. If the styloid process is joined to the mineralised stylomandibular or stylohyoid ligament by a single pseudo elongation it's considered to be pseudo elongated. The styloid process was considered as the segmented type if it consisted of continuous long or short non continuous portions or interrupted segments. For the assessment of calcified outline type of mineralisation of the styloid process the presence of a reminiscence of a long bone with a thin radiographic cortex and a central radiolucency that constituted most of the process was required. The styloid process was considered as the partially calcified type if there was a thicker radiopaque outline, with almost complete opacification and with an occasional discontinu- ous radiolucent core. The modular complex type of styloid process was assessed by the presence of scalloped outline with or without complete or partial calcification and varying degrees of central radiolucency. If the styloid process was completely opaque with no inner radiolucent core then it was considered to be a completely calcified type of mineralisation. Visual assessment of the type of calcification of the style process was done, along with the type of elongation. OPGs with incomplete styloid processes, and distorted images were omitted. The data obtained was tabulated in excel sheet, and was transferred to SPSS software by IBM, in which the variables were defined. The variables recorded were age, gender, type of elongation, type of mineralisation.

\section{Statistical analysis}

The values and variables were tabulated and analysed using the SPSS software by IBM. Chi-square tests were done to assess the correlation and association. $\mathrm{p}$ value of less than 0.05 was considered as statistically significant. The independent variables were age, gender. while the dependent variable is where the type of elongation, type of calcification on the right and left sides.

\section{Results and Discussion}

On the right side the types of elongation observed were 35 $(35 \%)$ of the styloid process were elongated, $19(19 \%)$ pseudo elongated, $6(6 \%)$ segmented and the rest $40(40 \%)$ were normal. $35(35 \%)$ of the styloid process were elongated, $24(24 \%)$ pseudo elongated, $3(3 \%)$ segmented and $38(38 \%)$ normal on the left side. On the right side the incidence patterns of mineralisation observed were 48 ( $48 \%$ ) of styloid process were partially calcified, $21(21 \%)$ calcified outline, $15(15 \%)$ completely calcified, 16 $(16 \%)$ nodular complexes. 55 (55\%) of the styloid processes were partially calcified. 19 (19\%) calcified outline, 18 (18\%) completely calcified, $6(6 \%)$ nodular complex on the left side. The elongation of the right styloid process was $21(21 \%)$ in number and was commonly seen in the $41-70$ years of age group. The segmented type had equal incidence in both age groups on the right side $3(3 \%)$. Pseudo elongated type was slightly higher in the 41-70 age group $10(10 \%)$ than the 10-40 age group $9(9 \%)$. On the left side segmented type of styloid process was only found $3(3 \%)$ in the 10 40 years age group. The elongation of the left styloid process was $21(21 \%)$ in number and was commonly seen in the $41-70$ years of age group. Pseudo elongated type of left styloid process had common incidence in both age groups $12(12 \%)$. On the right side, Completely calcified styloid process was commonly seen in 41-70 years of age on the right side $8(8 \%)$. Partially calcified had the highest incidence of $30(30 \%)$ in the 10-40 age group. Completely calcified styloid process was commonly seen in 10-40 years of age on the right side $12(12 \%)$ and Partially calcified had the highest incidence of $32(32 \%)$ in 10-40 years of age on the left side.

The styloid process is in close proximity to the vital structures of the face and the neck. Such as the facial nerve, the glossopharyngeal nerve, the internal and the external carotid arteries and the internal jugular vein, due to which it has gained importance in the healthcare system [14]. The aetiology of the elongation and the morphological changes of the styloid process is still unproven, nevertheless there are many suggested hypotheses namely, the elongation may be a result of ossification of the stylohyoid ligament of the styloid process itself. Other hypotheses and theories 
Graph 1. This graph represents the count of type of elongation present on the right side. $X$ axis gives the type of elongation and the $\mathrm{Y}$ axis represents the number of patients with different types of elongation. 35 patients (35\%) had elongated styloid process in the right side, 19 patients $(19 \%)$ had pseudo elongated type of styloid process, 6 patients $(6 \%)$ had segmented type of styloid process and 40 patients $(40 \%)$ had normal type of styloid processes in the right side.

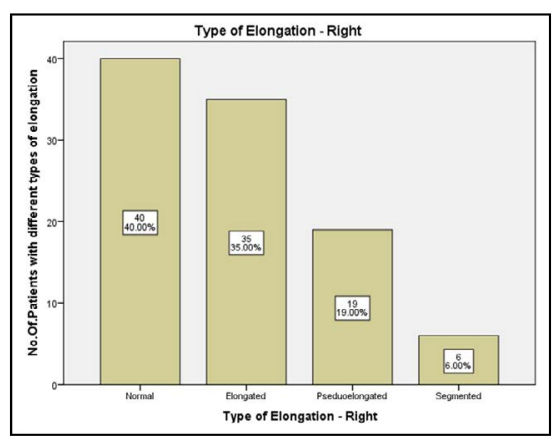

Graph 2. This graph represents the count of the type of elongation present on the left side. The $\mathbf{X}$ axis represents the type of elongation of the styloid process on the left side, and the $\mathrm{Y}$ axis represents the number of patient with different types of elongation. 35 patients $(35 \%)$ had elongated styloid process in the left side, 24 patients (24\%) had pseudo elongated type of styloid process, 3 patients $(3 \%)$ of the patients had segmented type of styloid process and 38 patients $(38 \%)$ had normal type of styloid processes in the left side.

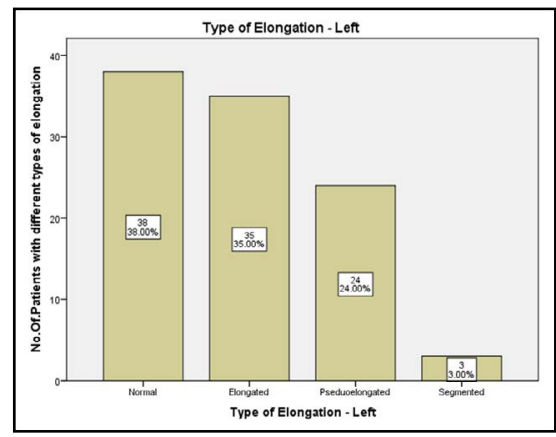

Graph 3. This graph represents the count of the type of mineralisation present on the right side. The $X$ axis represents the type of mineralisation of the styloid process on the right side, and the $Y$ axis represents the number of patients with different patterns of mineralisation. 48 patients $(48 \%)$ had partially calcified type of styloid process. 21 patients $(21 \%)$ had calcified outline type of mineralisation of the styloid process. 15 patients $(15 \%)$ had completely calcified type of styloid process, and 16 patients $(16 \%)$ had nodular complex type of mineralisation in their right styloid process.

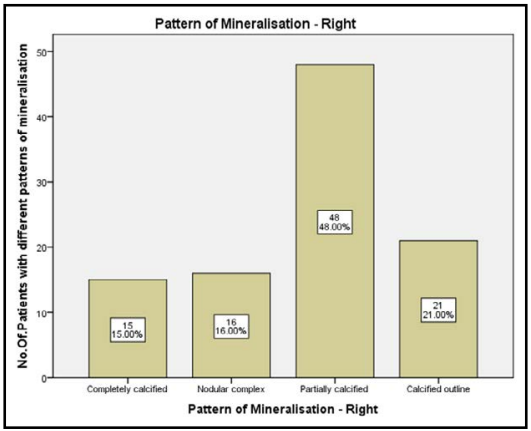

include reactive hyperplasia, anatomic variance, ageing developmental anomalies, degenerative process, and genetic hypothesis [15]. Though the styloid process can be viewed and assessed on the panoramic radiographs, there are chances for distortions, as OPGs are not obtained for the purpose of assessment of the styloid process.

Previous studies done by G. Roopashri et al, Elongated styloid process was seen in 107 patients out of 300, aged between 1070 years of age, it was concluded that the female patients had higher incidence of styloid elongation than the male patients, and the left styloid was more commonly elongated than the right styloid process [16]. In the study done by O. Onbas et al, in Turkey, there were no significant differences in the styloid process, among
Male and female subjects [17]. There were significant differences between the sizes, elongation and also angulations among gender. In the research done by Kodhuri Sridevi et al, The female subjects had higher incidences of elongated styloid process compared to the male population. The prevalence of calcified outline type of mineralisation of the styloid process was more commonly prevalent in the male population compared to the female study population [18]. In M B Bagga et al, study conducted among the male and female population of Madhura, in North India. The incidence of elongation was $52 \%$ which was the highest among the incidence as of all previous studies in Indian population [19]. Another asymptomatic elongation of the styloid process was found in the Turkey population by Ilguy et al, which was $80.8 \%$ [20]. In the study by Vieira et al, it was observed that the incidence 
Graph 4. This graph represents the count of the type of mineralisation present on the left side. The $\mathrm{X}$ axis represents the type of mineralisation of the styloid process on the left side, and the $\mathrm{Y}$ axis represents the number of patients with different patterns of mineralisation. 55 patients $(55 \%)$ had partially calcified type of styloid process. 19 patients $(19 \%)$ had calcified outline type of mineralisation of the styloid process, 18 patients $(18 \%)$ had completely calcified type of styloid process and 6 patients $(6 \%)$ had nodular complex type of mineralisation in their left styloid process.

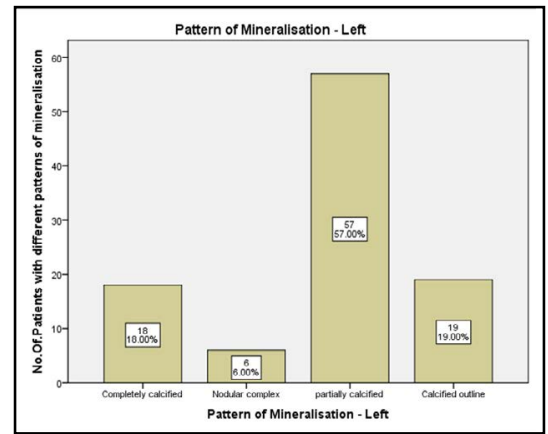

Graph 5. This bar graph compares the association of elongation of the right side styloid process across different age groups. The $X$ axis represents the types of elongation while the $y$ axis represents the number of patients with different types of elongation. The 41-70 years age group (green colour) has a higher incidence of elongated styloid process compared to the 10-40 years age group (blue colour) and this difference is statistically significant. (Chi-square test, $\mathrm{p}$ value: $0.008 \mathrm{p}(<0.05$, proving statistically significant association)) implying an association between the type of elongation and the age group.

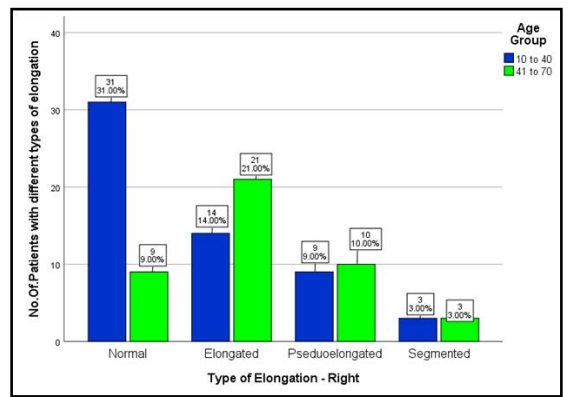

Graph 6. This bar graph compares the association of elongation of the left side styloid process across different age groups. The $\mathrm{X}$ axis represents the types of elongation while the $\mathrm{Y}$ axis represents the number of patients with different types of elongation. The 41-70 years age group (green colour) has a higher incidence of elongated styloid process compared to the $10-40$ years age group (blue colour) and this difference is statistically significant. (Chi-square test, $\mathrm{p}$ value: $0.011 \mathrm{p}(<0.05$, proving statistically significant association)) implying an association between the type of elongation and the age group.

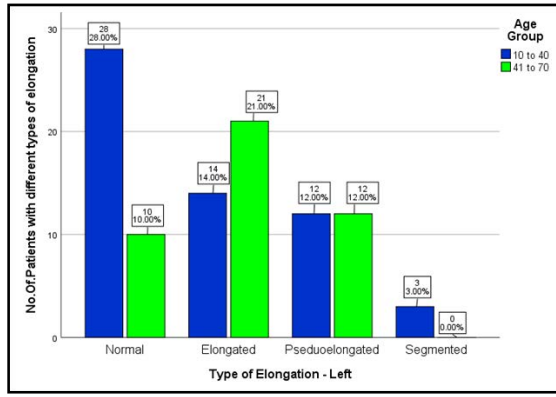

Graph 7. This bar graph compares the association of pattern of mineralisation of the right side styloid process across different age groups. The $\mathrm{X}$ axis represents the patterns of mineralisation while the $\mathrm{Y}$ axis represents the number of patients with different patterns of mineralisation. The 10-40 years age group (blue colour) has a higher incidence of partially calcified right styloid process compared to the 41-70 years age group (green colour), however this difference is not statistically significant. (Chi-square test, $\mathrm{p}$ value: 0.210 ( $\mathrm{p}>0.05$ which is statistically not significant)) implying no association between the pattern of mineralisation and the age group.

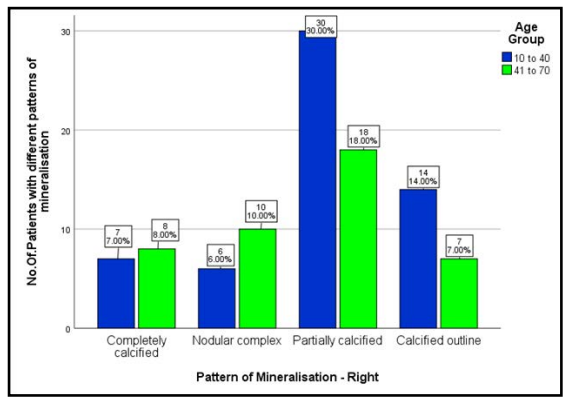


Graph 8. This bar graph compares the association of pattern of mineralisation of the left side styloid process across different age groups. The $X$ axis represents the patterns of mineralisation while the $Y$ axis represents the number of patients with different patterns of mineralisation. The 10-40 years age group (blue colour) has a higher incidence of partially calcified left styloid process compared to the 41-70 years age group (green colour), however this difference is not statistically significant. (Chi-square test, $\mathrm{p}$ value: 0.556 ( $\mathrm{p}>0.05$ which is statistically not significant)) implying no association between the pattern of mineralisation and the age group.

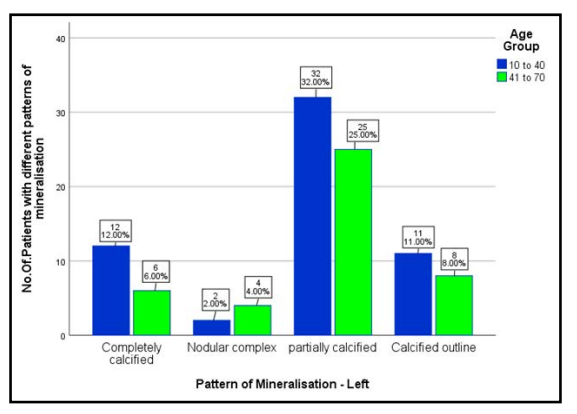

of elongation of the styloid process was $43.89 \%$ in the Brazilian population [21]. In the study by Hettiarcachichi et al, which was conducted in the Sri Lankan population, the incidence of styloid process elongation was found to be present in $59.5 \%$ in the study population [22]. In a study done by R. Sudhakar reddy et al, in Andhra Pradesh, south India.The most common type of mineralisation of the styloid process was the completely calcified type, the incidence of completely calcified type of styloid process was $58 \%$ in the study population [23]. In a study by Roghith Kannan et al, in dry skulls of south India, the length of the styloid process in the right side was $9.3 \mathrm{~mm}$ and $8.9 \mathrm{~mm}$ in the right and left sides respectively [24]. In the study by N. Akash et al, on South Indian dry skulls, the incidence of elongated styloid process was 4\% [25]. In a study by Divyadharshini et al, the mean length of right and left styloid process in males $3.34 \mathrm{~cm}$ and $2.95 \mathrm{~cm}$ respectively. In females, the mean length $3.35 \mathrm{~cm}$ and $3.05 \mathrm{~cm}$ on the right and left sides respectively. The length of the styloid process was longer on the right side when compared to the left side [26]. In accordance with the present study, the elongation of the styloid process on the right and left sides were $35 \%$. The incidence of the partially calcified type of calcification of the styloid process was the most common $46 \%$ on the right side and $57 \%$ on the left side. The variations in the results obtained between the present and previous studies could have been caused because of differences in ethnicity and different geographical regions of the study populations and the size of the study sample.

The problems associated with an elongated styloid process is mainly pain which may be accentuated by a poor oral hygiene [27, 28]. The diagnosis of this condition clinically remains a challenge as the pain may be mistaken due to other irrelevant conditions $[29,30]$. The management from the medical standpoint just consists of administration of pain relieving medications. There have been several studies in the past which have mentioned corticosteroids for the management of the pain due to elongated styloid process. But they do not carry any therapeutic value other than reducing the inflammation in the tissues $[31,32]$.

The limitations of the present study was that it has been geographically restricted to a single population, and the data samples belong to the patients of same or similar ethnic origins. The patients data used for this present study belongs to a single university. Other limitations were, unlike the previous studies the sample size was limited, due to distorted and obscure OPGs. However the main limitations of the present study was that there were chances of error in the manual interpretation of the styloid process using the OPGs, as the evaluation of the styloid process using the OPGs can be subjected to errors. However there have been several case based studies [33, 34] and original studies done in this database $[35,36]$.

The limitations of the present study can be overcome by selecting a larger study population, and by using different and better radiographic methods for the morphometric analysis of the styloid process. In the future, this can be avoided by the usage of better radiographic methods or other types of radiographs such as lateral cephalograms, computed tomography, CBCT etc.

\section{Conclusion}

Within the limits of this study it can be concluded that most styloid processes were of the normal dimensions and those styloid processes which were elongated were partially calcified types in the age group of 10-40 years. This study can prove clinically relevant as assessment of different types of elongation and different types of calcification of the styloid process may help in the diagnosis of atypical orofacial pain.

\section{Acknowledgement}

This research was done under the supervision of the Department of Research of Saveetha Dental College and Hospitals. We sincerely show gratitude to the corresponding guide who provided insights and expertise that greatly assisted the research.

\section{References}

[1]. Contractor JB, Vaniya VH, Desai U. Eagle syndrome-An elongated styloid process. Journal of the Anatomical Society of India. 2017 Aug 1; 66: S89-90.

[2]. de Andrade KM, Rodrigues CA, Watanabe PC, Mazzetto MO. Styloid process elongation and calcification in subjects with tmd: clinical and radiographic aspects. Braz Dent J. 2012; 23(4): 443-50. PMID: 23207864.

[3]. Yasmeenahamed S, Laliytha BK, Sivaraman S, Ambiga P, Dineshshankar J, Sudhaa M. Eagle's syndrome - Masquerading as ear pain: Review of literature. J Pharm Bioallied Sci. 2015 Aug; 7(Suppl 2): S372-3. PMID: 26538879.

[4]. Custodio AL, Silva MR, Abreu MH, Araújo LR, de Oliveira LJ. Styloid Process of the Temporal Bone: Morphometric Analysis and Clinical Implications. Biomed Res Int. 2016; 2016: 8792725. PMID: 27703982.

[5]. Natsis K, Repousi E, Noussios G, Papathanasiou E, Apostolidis S, Piagkou $M$. The styloid process in a Greek population: an anatomical study with clinical implications. Anat Sci Int. 2015 Mar; 90(2): 67-74. PMID: 24664363. 
[6]. Koshy JM, Narayan M, Narayanan S, Priya BS, Sumathy G. Elongated styloid process: A study. J Pharm Bioallied Sci. 2015 Apr; 7(Suppl 1): S131-3. PMID: 26015690.

[7]. Arora V, Shetti A, Keluskar V. Eagle syndrome: A review of current diagnostic criteria and evaluation strategies. Journal of Indian Academy of Oral Medicine and Radiology. 2008 Jan 1; 20(1): 1.

[8]. Rayna A, Francis Y, Gouthaman P, Begum Z, Baskaran Sb, Guruswami K, et al. Morphometric Study of Proximal and Distal End of Radius and its Clinical Significance. Journal of Clinical \& Diagnostic Research. 2018 Sep $1 ; 12(9)$.

[9]. Steele JC, Clark HJ, Hong CH, Jurge S, Muthukrishnan A, Kerr AR, et al. World Workshop on Oral Medicine VI: an international validation study of clinical competencies for advanced training in oral medicine. Oral Surg Oral Med Oral Pathol Oral Radiol. 2015 Aug; 120(2): 143-51.e7. PMID: 25861956.

[10]. Misra SR, Shankar YU, Rastogi V, Maragathavalli G. Metastatic hepatocellular carcinoma in the maxilla and mandible, an extremely rare presentation. Contemp Clin Dent. 2015 Mar; 6(Suppl 1): S117-21. PMID: 25821363.

[11]. Chaitanya NC, Muthukrishnan A, Babu DBG, Kumari CS, Lakshmi MA, Palat G, et al. Role of Vitamin E and Vitamin A in Oral Mucositis Induced by Cancer Chemo/Radiotherapy- A Meta-analysis. J Clin Diagn Res. 2017 May; 11(5): ZE06-ZE09. PMID: 28658926.

[12]. Chaitanya NC, Muthukrishnan A, Krishnaprasad CMS, Sanjuprasanna G, Pillay P, Mounika B. An Insight and Update on the Analgesic Properties of Vitamin C. J Pharm Bioallied Sci. 2018 Jul-Sep; 10(3): 119-125. PMID: 30237682 .

[13]. Subha M, Arvind M. Role of magnetic resonance imaging in evaluation of trigeminal neuralgia with its anatomical correlation. Biomedical and Pharmacology Journal. 2019 Mar 25; 12(1): 289-96.

[14]. Murthy PS, Hazarika P, Mathai M, Kumar A, Kamath MP. Elongated styloid process: an overview. Int J Oral Maxillofac Surg. 1990 Aug; 19(4): 230-1. PMID: 2120364.

[15]. Bruno G, De Stefani A, Balasso P, Mazzoleni S, Gracco A. Elongated styloid process: An epidemiological study on digital panoramic radiographs. J Clin Exp Dent. 2017 Dec 1; 9(12): e1446-e1452. PMID: 29410761.

[16]. Roopashri G, Vaishali MR, David MP, Baig M. Evaluation of elongated styloid process on digital panoramic radiographs. J Contemp Dent Pract. 2012 Sep 1; 13(5): 618-22. PMID: 23250163.

[17]. Onbas O, Kantarci M, Murat Karasen R, Durur I, Cinar Basekim C, Alper $\mathrm{F}$, et al. Angulation, length, and morphology of the styloid process of the temporal bone analyzed by multidetector computed tomography. Acta Radiol. 2005 Dec; 46(8): 881-6. PMID: 16392614.

[18]. Sridevi K, Mahesh N, Krishnaveni B, Deepika ADN, Thejasri V, Leninson BHD. Evaluation of Styloid Process and Its Anatomical Variations: A Digital Panoramic Study with Systematic Review. J Int Soc Prev Community Dent. 2019 May-Jun; 9(3): 256-262. PMID: 31198698.

[19]. Bagga MB, Kumar CA, Yeluri G. Clinicoradiologic evaluation of styloid process calcification. Imaging Sci Dent. 2012 Sep; 42(3): 155-61. PMID: 23071965.

[20]. Ilgüy M, Ilgüy D, Güler N, Bayirli G. Incidence of the type and calcification patterns in patients with elongated styloid process. J Int Med Res. 2005 Jan-
Feb; 33(1): 96-102. PMID: 15651721.

[21]. Vieira EM, Guedes OA, Morais SD, Musis CR, Albuquerque PA, Borges ÁH. Prevalence of Elongated Styloid Process in a Central Brazilian Population. J Clin Diagn Res. 2015 Sep; 9(9): ZC90-2. PMID: 26501021.

[22]. Hettiarachchi PVKS, Jayasinghe RM, Fonseka MC, Jayasinghe RD, Nanayakkara CD. Evaluation of the styloid process in a Sri Lankan population using digital panoramic radiographs. J Oral Biol Craniofac Res. 2019 Jan-Mar; 9(1): 73-76. PMID: 30302305.

[23]. Sudhakara Reddy R, Sai Kiran Ch, Sai Madhavi N, Raghavendra MN, Satish A. Prevalence of elongation and calcification patterns of elongated styloid process in south India. J Clin Exp Dent. 2013 Feb 1; 5(1): e30-5. PMID: 24455048.

[24]. Kannan R, Thenmozhi MS. Morphometric Study of Styloid Process and its Clinical Importance on Eagle's Syndrome. Research Journal of Pharmacy and Technology. 2016; 9(8): 1137-9.

[25]. Akash N, Thenmozhi MS, Lakshmanan G. Elongation of styloid processEagle's syndrome. Drug Invention Today. 2019 Aug 1; 12(8).

[26]. Divyadharshini JK. Assessment of styloid process length in orthopantomogram—a radiographic study. Int J Pharm Bio Sci. 2016; 7(4): 503-6.

[27]. Subashri A, Maheshwari TN. Knowledge and attitude of oral hygiene practice among dental students. Research Journal of Pharmacy and Technology. 2016; 9(11): 1840-2.

[28]. Rohini S, Kumar VJ. Incidence of dental caries and pericoronitis associated with impacted mandibular third molar-A radiographic study. Research Journal of Pharmacy and Technology. 2017; 10(4): 1081-4.

[29]. Maheswari TNU, Venugopal A, Sureshbabu NM, Ramani P. Salivary micro RNA as a potential biomarker in oral potentially malignant disorders: A systematic review. Ci Ji Yi Xue Za Zhi. 2018 Apr-Jun; 30(2): 55-60. PMID: 29875583.

[30]. Venugopal A, Uma Maheswari TN. Expression of matrix metalloproteinase-9 in oral potentially malignant disorders: A systematic review. J Oral Maxillofac Pathol. 2016 Sep-Dec; 20(3): 474-479. PMID: 27721614.

[31]. Dharman S, Muthukrishnan A. Oral mucous membrane pemphigoid - Two case reports with varied clinical presentation. J Indian Soc Periodontol. 2016 Nov-Dec; 20(6): 630-634. PMID: 29238145.

[32]. Muthukrishnan A, Bijai Kumar L. Actinic cheilosis: early intervention prevents malignant transformation. BMJ Case Rep. 2017 Mar 20; 2017: bcr2016218654. PMID: 28320702.

[33]. Patil SR, Maragathavalli G, Araki K, Al-Zoubi IA, Sghaireen MG, Gudipaneni RK, et al. Three-rooted mandibular first molars in a Saudi Arabian population: a CBCT study. Pesquisa Brasileira em Odontopediatria e Clinica Integrada. 2018 Aug 27; 18(1): 4133.

[34]. Muthukrishnan A, Warnakulasuriya S. Oral health consequences of smokeless tobacco use. Indian J Med Res. 2018 Jul; 148(1): 35-40. PMID: 30264752.

[35]. Dharman S, Muthukrishnan A. Oral mucous membrane pemphigoid - Two case reports with varied clinical presentation. J Indian Soc Periodontol. 2016 Nov-Dec; 20(6): 630-634. PMID: 29238145.

[36]. Choudhury P, Panigrahi RG, Maragathavalli, Panigrahi A, Patra PC. Vanishing roots: first case report of idiopathic multiple cervico-apical external root resorption. J Clin Diagn Res. 2015 Mar; 9(3): ZD17-9. PMID: 25954713. 